\title{
Derin Öğrenme Tekniklerini Kullanarak Akciğer X-Ray Görüntülerinden COVID-19 Tespiti
}

\author{
Ferhat Bozkurt $^{1 *}$ \\ 1* Atatürk University, Faculty of Engineering, Department of Computer Engineering, Erzurum, Turkey (ORCID: 0000-0003-0088-5825), fbozkurt@ atauni.edu.tr \\ (2nd International Conference on Access to Recent Advances in Engineering and Digitalization (ARACONF)-10-12 March 2021)
}

(DOI: $10.31590 /$ ejosat.898385)

ATIF/REFERENCE: Bozkurt, F. (2021). Derin Öğrenme Tekniklerini Kullanarak Akciğer X-Ray Görüntülerinden COVID-19 Tespiti. Avrupa Bilim ve Teknoloji Dergisi, (24), 149-156.

$\ddot{O} \mathbf{z}$

COVID-19 salgını tüm dünyada hızla yayılarak küresel bir pandemi haline gelmiştir. Bu salgın, günlük yaşamda hem halk sağlığı hem de küresel ekonomi üzerinde yıkıcı bir etkiye sahip olmuştur. Bu salgının daha fazla yayılmasını önlemek ve etkilenen hastaları hızla tedavi etmek için pozitif vakaları olabildiğince erken tespit etmek çok önemlidir. COVID-19 enfeksiyonunun hızlı bir şekilde ve yüksek doğrulukta teşhisini sağlayan herhangi bir yardımcı araç uzmanlar için faydalıdır. Bu anlamda, X-Ray tomografik görüntüleme COVID-19 teşhisinde kolay erişilebilir alternatif bir araçtır. Radyoloji görüntüleme teknikleri kullanılarak elde edilen son bulgular, bu tür görüntülerin COVID-19 virüsü hakkında çarpıcı bilgiler içerdiğini göstermektedir. Radyolojik görüntülemeyle birlikte gelişmiş yapay zekâ ve makine öğrenmesi tekniklerinin uygulanması, bu hastalığın doğru tespiti için yardımcı olabilir. X-ray görüntüleri şüpheli vakaların erken tespitine yardımcı olabilse de, çeşitli viral ve bakteriyel pnömoni (zatürre) görüntüleri COVID-19 ile benzerdir ve benzer özellikler içermektedir. Dolayısıyla radyologların viral ve bakteriyel pnömoni gibi benzer akciğer hastalıklarını COVID-19'dan ayırt etmesi zordur. Bu bağlamda, COVID-19 semptomlarının viral pnömoniye benzer olması, yanlış tanılara yol açabilmektedir. Bu çalışmada, kurulan farklı modeller ile akciğer X-Ray görüntülerini COVID-19, normal ve viral pnömoni (zatürre) hastalar olarak sınıflandırabilen derin öğrenme tekniklerinin bir karşılaştırması yapılmıştır. Bu çalışmada, 11 farklı derin öğrenme tekniği üzerinde çalışılmıştır. Günümüzde popüler olan evrişimli sinir ağları tabanlı farklı tekniklerin aynı veri kümesi üzerinde deneysel çalışmaları yapılarak her bir tekniğin performans değerlendirmesi yapılmış ve en iyi tahminleme yöntemi belirlenmiştir. Yapılan deneysel çalışmalarda, en yüksek doğruluk değeri \%97.17 ile DenseNet121 modeli ile elde edilmiştir.

Anahtar Kelimeler: Derin öğrenme, Evrişimli sinir ağları, Sınıflandırma, Akciğer X-Ray görüntüleri, COVID-19.

\section{COVID-19 Detection from Chest X-Ray Images Using Deep Learning Techniques}

\begin{abstract}
COVID-19 has spread rapidly all over the world and has become a global pandemic. This epidemic has a devastating impact on both public health and the global economy in everyday life. Detecting positive cases as early as possible is crucial to prevent the further spread of this epidemic and to treat affected patients quickly. Any tool that provides a fast and highly accurate diagnosis of COVID19 infection is useful to experts. In this context, X-Ray tomographic imaging is an easily accessible alternative tool in the diagnosis of COVID-19. Recent developments using radiology imaging techniques show that such images contain interesting information about the COVID-19. The application of advanced artificial intelligence and machine learning techniques combined with radiological imaging can assist to accurate detection of this disease. Although X-Ray images can help to diagnose suspected cases early, various viral and bacterial pneumonia images are similar to COVID-19 and include similar features. Therefore, it is difficult for radiologists to distinguish similar lung diseases like viral and bacterial pneumonia from COVID-19. In this context, the similarity of COVID-19
\end{abstract}

* Corresponding Author: fbozkurt@atauni.edu.tr 
symptoms to viral pneumonia can lead to misdiagnosis. In this study, deep learning techniques that can classify chest X-Ray images as COVID-19, normal and viral pneumonia are compared. In this study, 11 different deep learning techniques have been studied. Experimental studies of different techniques based on convolutional neural networks, which are popular today, have been studied on the same dataset to evaluate the performance of each technique and the best prediction method has been determined. In experimental studies, the highest accuracy value is obtained with the DenseNet121 model with $97.17 \%$.

\section{Keywords: Deep learning, Convolutional neural network, Classification, Chest X-ray images, COVID-19.}

\section{Giriş}

Göğüs röntgeni görüntüleri tüberküloz, infiltrasyon, atelektazi, pnömoni ve fitık gibi çeşitli akciğer hastalıklarının izlenmesinde ve incelenmesinde kullanılmaktadır. Üst solunum yolu ve akciğer enfeksiyonu olarak ortaya çıkan COVID-19, ilk olarak 2019'un sonlarında Çin'in Wuhan eyaletinde ortaya çıktı. Çoğunlukla hava yolu ve temas ile bulaşmakta olup, enfekte olanların akciğerlerini büyük ölçüde etkilediği görülmüştür. Virüs o zamandan beri hızla yayıldı ve küresel bir salgın haline geldi. Vaka sayısı ve buna bağlı ölümler her gün artmaya devam etmektedir (WHO, 2020). X-Ray ile akciğer görüntüleme, akciğer koşullarının hızlı incelenmesi için en yaygın kullanılan ve erişilebilir yöntemlerden biridir. Akciğer X-Ray görüntüleri hızlı bir şekilde radyologlar tarafından analiz edilmeye hazırdır. Gögüs röntgeni görüntülerinin, COVID-19'un akciğer dokusuna neden olduğu etkilerin izlenmesinde faydalı olduğu gösterilmiştir. Dolayısıyla göğüs röntgeni görüntüleri, COVID19'un teşhisinde kullanılabilir (Ismael \& Şengür, 2021). X-Ray ile akciğer grafisi, hastane kaynaklarını verimli bir şekilde tahsis etmek için COVID-19 olmayan hastaları triyaj (hastaların tıbbî olarak sınıflandırılma) yapmakta etkin bir araçtır. Bununla birlikte, COVID-19'un tıbbi görüntüleri ile yaygın grip gibi diğer viral enfeksiyonların neden olduğu pnömoni arasında birçok ortak özellik vardır. Bu benzerlik, uzman radyologların COVID19 vakalarını ayırmada tanı koymalarını zorlaştırmaktadır. COVID-19 ve COVID-19 olmayan akciğer X-Ray görüntülerinin sınıflandırılması için güvenilir bir yöntem, COVID-19 olmayan vakaların triyaj sürecini hılandırabilir ve hastane kaynaklarının COVID-19 vakalarına tahsis edilmesini en üst düzeye çıkarabilir (Dai vd., 2020).

Literatürde, hastalık tespiti için göğüs röntgeni görüntülerini kullanan çeşitli makine öğrenmesi ve derin öğrenme yöntemlerine dayalı yaklaşımlar mevcuttur. Pathak vd. (2020), COVID-19 hastalığını tespit etmek için bir transfer öğrenme yaklaşımı kullanan önceden eğitilmiş ResNet32 modeline dayalı bir yaklaşım sundular. Çalışmada, 852 görüntü (413 COVID-19 ve 139 normal) içeren bir veri kümesinde bulunan akciğer BT taraması görüntüleri kullanılarak testler yaptılar. Deneysel çalışmalarında önerilen model ile sırasıyla \%96.22 ve \%93.01'e varan eğitim ve test doğruluğu elde ettiler. Zhao vd. (2020), COVID-19 tespiti için önceden eğitilmiş DenseNet modeline dayalı bir yöntem geliştirdiler. COVID-BT veri seti kullanılarak yapılan deneysel çalışmalarda \%84,7 doğruluk elde ettiler. Oğuz ve Yağanoğlu (2021), derin öğrenme tekniklerini kullanılarak akciğer BT görüntülerinden COVID 19 vakası tespiti için çeşitli sınıflandırma yöntemlerinin performansları değerlendirdiler. En iyi sonucu \% 95.18 başarı oranı ile ResNet-50 ve SVM sinıflandırma yöntemleri ile elde ettiler. Li vd. (2020), çalışmalarında 3.322 hastadan alınan 4.356 göğüs BT görüntüsünü içeren bir veri seti üzerinde COVID-19 hastalığını tespit etmek için önceden eğitilmiş ResNet50 mimarisine dayanan COVNet modeli kullanılarak \%90 duyarlılık elde ettiler. Asnaoui vd. (2020), X-Ray ve BT görüntüleri kullanarak pnömoninin sınıflandırılması için derin öğrenme tekniklerini kullandılar. Çalışmalarında, önceden eğitilmiş transfer öğrenme yaklaşımına dayalı çeşitli derin öğrenme (VGG16, VGG19, InceptionV3, DenseNet201, Xception, ResNet50, Inception ResNetV2 ve MobileNetV2) tekniklerinin performanslar1 incelendiler. Deneysel sonuçlarında en yüksek doğruluk \%96.61 ile ResNet50 modelinden elde ettiler. Xu vd. (2020), BT tarama görüntülerinden potansiyel olarak enfekte olmuş bölgeleri çıkarmak için önceden eğitilmiş bir üç boyutlu evrişimli sinir ağ (ESA) önerdiler. Deneysel sonuçlarda, Viral pnömoni, COVID19 ve sağlıklı denekler kullanılarak gerçekleştirilen tahminlemede \%86,7 doğruluk elde ettiler. Wang vd. (2020), göğüs radyografisi görüntülerinden COVID-19 hastalığının sınıflandırılması için önceden eğitilmiş ResNet50 mimarisini kullandılar. Çalışmalarında, COVIDx veri seti sağlıklı, pnömoni ve COVID-19 deneklerinden alınan verileri içerir. Deneysel sonuçlarına göre, ortalama \%93.4 doğruluk değeri elde ettiler. Narin vd. (2020), COVID-19 hastalığının sınıflandırılmasında $\mathrm{X}$-ışını görüntüleri için derin ESA tabanlı modeller kullandılar. ESA tabanl 1 modeller, (InceptionResNetV2, ResNet50 ve InceptionV3) göğüs röntgeni radyografilerini kullanarak koronavirüs pnömonisi ile enfekte olmuş denekleri tespit etmek için kullanıldı. Deneysel sonuçlara göre, en yüksek doğruluk \%98 ile ResNet50 modeliyle elde edildi. Kesim vd. (2019), akciğer X-Ray görüntü sınıflandırması için yeni bir ESA modeli önerdiler. Yazarlar önceden eğitilmiş ESA modellerinin pratik uygulamalarda zorluklar yarattığı bilinmesi nedeniyle küçük boyutlu bir ESA mimarisi geliştirdiler. Çalışmalarında 12 sınıflı bir akciğer görüntü veri seti kullanılmış ve testlerinde \%86 doğruluk elde etmişlerdir. Chouhan vd. (2020), bir topluluk modeli olarak uygulanan beş yeni derin transfer-öğrenme tabanlı modeli kullanarak göğüs röntgeni görüntülerinde pnömoni tespit ettiler. Yazarlar, geliştirdikleri topluluk derin modelini kullanarak \% 96.4 doğruluk değeri rapor ettiler. Bhandary vd. (2020), akciğer X-Ray görüntülerinden akciğer anormalliklerinin tespiti için AlexNet modelini değiştirdiler. Yeni bir "eşik filtresi" ve öznitelik topluluğu stratejisi ile \%96 sinıflandırma doğruluğu elde ettiler. Ho ve Gwak (2019), 14 göğüs hastalığının etkin sınıflandırılması için derin özellikler ve dört yerel doku tanımlayıcısı (SIFT, GIST, LBP ve HOG) kullanan özellik birleştirme yöntemini tercih ettiler. Farklı sınıflandırıcılar ile en yüksek \%84.62 doğruluk değeri elde ettiler.

$\mathrm{Bu}$ çalışmada, akciğer X-Ray görüntülerini COVID-19, normal ve viral pnömoni hastalar olarak sinıflandırabilen 11 farklı derin öğrenme tekniğinin aynı veri kümesi üzerinde performans değerlendirmesi ve karşılaştırması yapılmıştır (Şekil 1). Bu çalışmada en basit sinir ağından başlayarak en karmaşığa doğru sinir ağları ile en iyi tahminleme yöntemi araştırılmıştır. Çalışmanın geri kalanı aşağıdaki şekilde düzenlenmiştir. Bölüm 2'de materyal ve metottan bahsedilmiştir. Bu bölümde, deneysel çalışmada kullanılan veri setinden ve uygulaması yapılan derin öğrenme tekniklerinden bahsedilmiştir. Bölüm 3'de deneysel çalışmalar, Bölüm 4'de ise çalışmanın tartışma ve sonuçlar kısmına yer verilmiştir. 


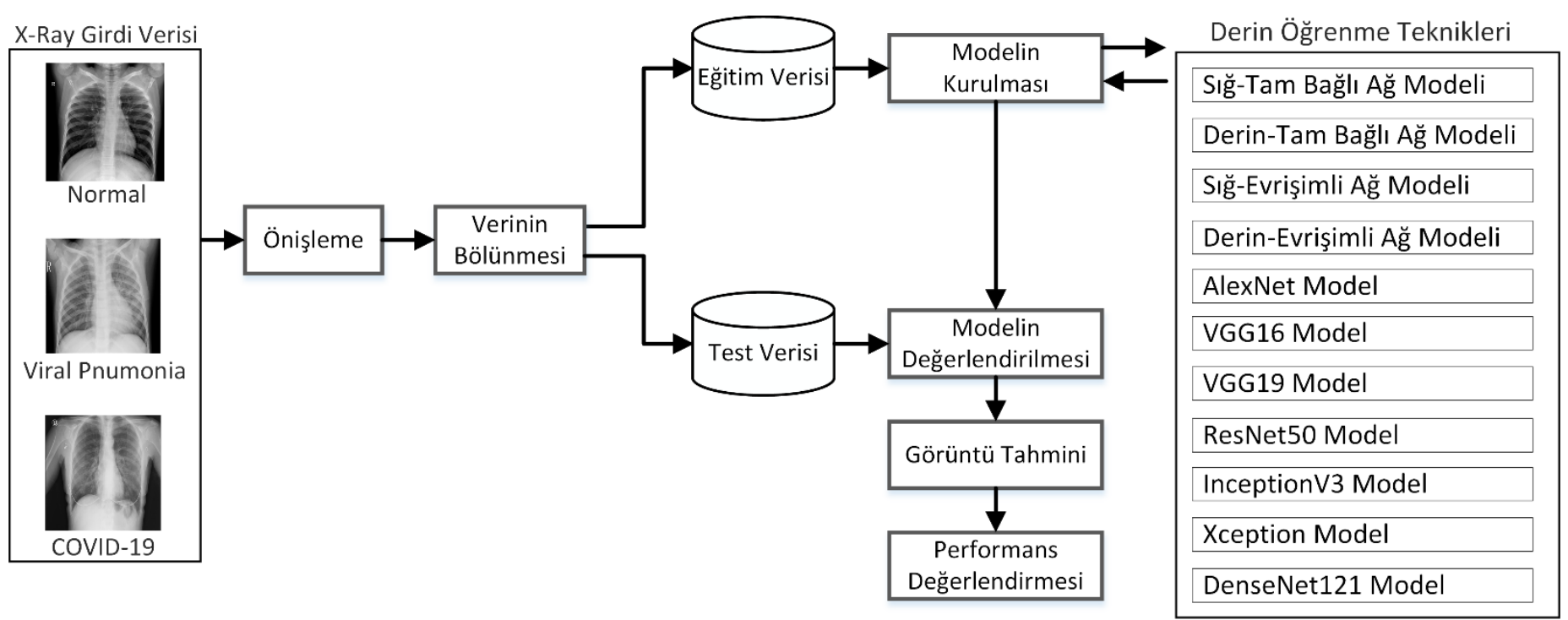

Şekil 1. Derin öğrenme teknikleri ile COVID-19 tespitinde farklı modellerin karşılaştırılmasında kullanılan mimari

\section{Materyal ve Metot}

\subsection{Materyal}

$\mathrm{Bu}$ çalışmada popüler veritabanı Kaggle'nin COVID-19 radyografi veritabanından elde edilen akciğer röntgeni görüntülerini kullanıldı (Chowdhury vd., 2020). Bu veri kümesi, COVID-19, viral pnömonili (zatürre) ve sağlıklı (normal) insanlara ait göğüs röntgen görüntüleri olmak üzere üç farklı sınıfa ait görüntülerden oluşturulmuştur. Toplam 3886 göğüs röntgeni görüntüsü olup, 1200 adet COVID-19 görüntüsü, 1345 adet viral pnömoni görüntüsü ve 1341 adet normal görüntü mevcuttur. Şekil 2'de bu veri kümesinden COVID-19, viral pnömoni ve normal vakaya ait görüntü örnekleri gösterilmektedir. Şekil 3'de çalışmada kullanılan X-Ray verisinin $\% 70$ eğitim, $\% 10$ doğrulama ve $\% 20$ test için ayrılmış hali üzerinden kategorik dağılımı gösterilmiştir.
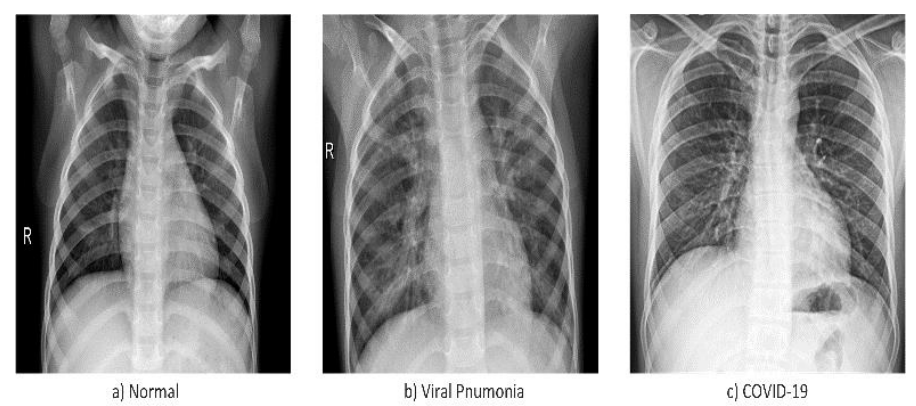

Şekil 2. Veri kümesindeki örnek Normal, Viral Pnömoni ve COVID-19 akciğer X-Ray görüntüleri

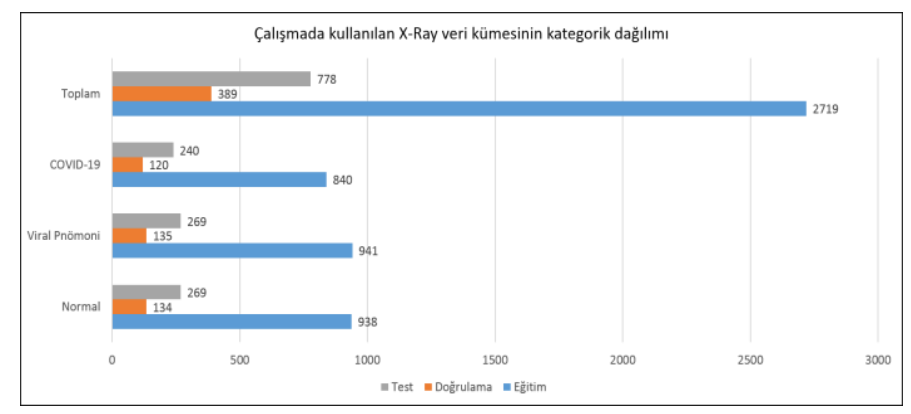

Şekil 3. Çalışmada kullanılan X-Ray veri kümesinin kategorik dağılımı
COVID-19 hastalarının röntgen görüntülerinde aşağıdaki bulgular görülmektedir. (1) Buzlu cam dansiteleri. (2) Havaboşluğu konsolidasyonu. (3) Buzlu cam görünümü ile crazy paving(kaldırım taşı) paterni. (4) Traksiyonel bronşiektaziler. COVID-19 ile benzer şekilde Pnömoni hastalarının röntgen görüntülerinde de aşağıdaki bulgular gözlenmektedir. (1) Retiküler opaklık (2) Buzlu cam görünümü. (3) Peribronkovasküler interstisyel kalınlaşma (4) Vasküler kalınlaşma (5) Bronşiyal duvar kalınlaşması (Ouchicha vd., 2020). Bu yönleriyle, COVID-19 ile Pnömoni akciğer röntgeni görüntüleri benzerdir ve benzer özelikler içermektedir. Dolayısıyla, bu görüntülere bakarak hastalıkların teşhisi noktasında yanlış tanı konulması ihtimali bulunmaktadır.

\subsection{Metot}

Derin öğrenme, makine öğrenimi tekniklerinin bir alt kümesidir. Günümüzde etkili bir makine öğrenimi tekniği olarak birçok uygulamada kullanılmaktadır. Derin öğrenmenin başarıyla kullanıldığı başlıca alanlar bilgisayarla görme, ses tanıma ve doğal dil işlemedir. Derin öğrenmenin yaygın başarısının nedeni, çıktıyı hesaplama yöntemidir. Derin öğrenmenin geleneksel tekniklere göre önemli bir avantajı, açık bir öznitelik çıkarma aşaması gerektirmemesidir. A $\breve{g}$, ham girdiyi alır ve istenen çıktıya eşler. Özellikler, manuel müdahale olmaksızın ağ tarafindan otomatik olarak öğrenilir. Bu modeller her ne kadar yüksek işlem gücü gerektirse de, günümüzde işlemci güçlerinin artmasıyla birlikte bu artık bir sorun olarak görülmemektedir. Derin öğrenme modelleri, artan sayıda gizli katmana sahip geleneksel ağların bir ilerlemesidir. Gizli katmanlar, bu ağların performansını büyük ölçüde artırır. Derin öğrenme teknikleri, orijinal görüntülerden görünmeyen görüntü özniteliklerini otomatik olarak ortaya çıkarabilir. Özniteliklerin çıkarılmasında herhangi bir insan müdahalesi ya da el ile özniteliklerin belirlenmesi yapılmaz. Derin öğrenme son zamanlarda, örüntü tanıma ve görüntü sınıflandırma işlemlerinde yaygın olarak kullanılır (Singh vd., 2020).

$\mathrm{Bu}$ çalışmada, akciğer X-Ray görüntülerini COVID-19, normal ve viral pnömoni (zatürre) hastalar olarak sınıflandırabilen farklı modeller ile derin öğrenme tekniklerinin karşılaştırılması yapılmıştır (Şekil 1). Bu çalışmada, 11 farklı derin öğrenme tekniği üzerinde çalışılmıştır. Bu teknikler; SığTam Bağlı Ağ Modeli (Shallow-Fully Connected Network 
Model), Derin-Tam Bağlı A $\breve{g}$ Modeli (Deep-Fully Connected Network Model), Sı̆g-Evrişimli A $\breve{g}$ Modeli (ShallowConvolutional Network Model), Derin-Evrişimli A $\breve{g}$ Modeli (Deep-Convolutional Network Model), VGG16, VGG19, ResNet50, InceptionV3, Xception, AlexNet, DenseNet121 modeldir. $\mathrm{Bu}$ aşamada, veri kümesi üzerinde deneysel çalışmaları ve karşıllaştırmaları yapılan her bir modele ait daha fazla bilgiye yer verilmiştir.

\subsubsection{Sı̆̆ ve Derin-Tam Bağll Ăg Modelleri}

Sinir Ağının birçok gizli katmandan oluştuğu bilinmektedir. Sı̆̆ sinir ağları yalnızca bir kaç gizli katmandan oluşur. Sığ bir sinir ağını anlamak, derin bir sinir ağının içinde tam olarak neler olup bittiğine dair bir fikir vermektedir. $\mathrm{Bu}$ çalışmada da öncelikle bir sığ sinir ağı modeli kurulmuş daha sonra daha fazla gizli katmanlar ile derin bir sinir ağı modeli uygulanmış ve sonuçlar alınmıştır. Bu aşamada, oluşturulan sığ sinir ağında dört gizli katman, derin sinir ağında ise dokuz gizli katman ve daha fazla nöron bulunmaktadır.

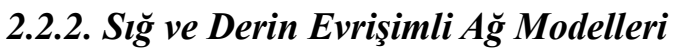

Evrişimli sinir ağı (ESA), derin öğrenmede yaygın olarak bilgisayarla görme (Hassaballah \& Awad, 2020) ve doğal dil işleme (Otter vd., 2020) çalışmalarına uygulanan bir derin sinir ağı sınıfıdır. ESA, esasında çok katmanlı algılayıcıların (multilayer perceptron) düzenli bir versiyonudur. Bir ESA, bir giriş katmanından, birden çok gizli katmandan ve bir çıktı katmanından oluşur. ESA, evrişim (convolution) ve havuzlama (pooling) olmak üzere iki temel işlem içerir. Gizli katmanlar yapısal olarak evrişimli katmanlar, ReLU (aktivasyon işlevi) katmanları, havuz katmanları, tamamen bağlı katmanlar ve normalleştirme katmanlarını içerir. Çoklu filtre kullanan evrişim işlemi, veri setinden ilgili uzamsal bilgilerin korunabileceği özellikleri (özellik haritası) çıkarabilir. Alt örnekleme olarak da adlandırılan havuzlama işlemi, evrişim işleminden öznitelik haritalarının boyutluluğunu azaltmak için kullanılır. Maksimum havuzlama ve ortalama havuzlama, ESA'da kullanılan en yaygın havuzlama işlemleridir. ESA'nın karmaşıklığı nedeniyle RELU, eğitimdeki gradyanı geri yayılım yoluyla aktarmak için kullanılan bir aktivasyon işlevidir. Diğer sınıflandırma algoritmaları ile karşılaştırıldığında, ESA çok daha az ön işlem gerektirir ve eğitim sayısı arttıkça daha iyi sonuçlar verebilir.

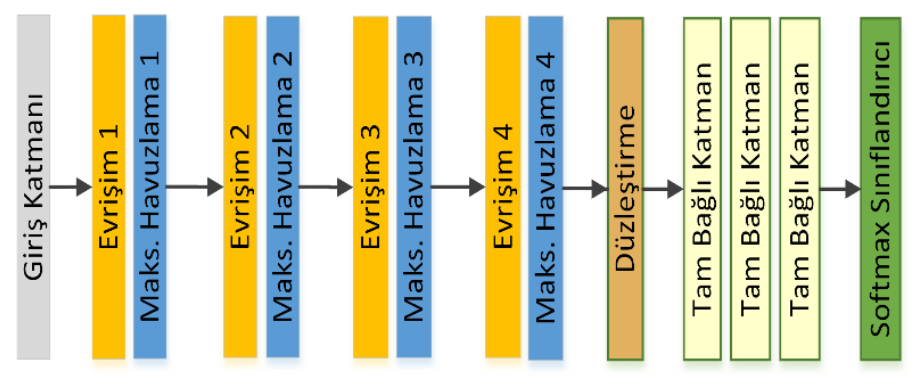

Şekil 4. Bu çalışmada oluşturulan derin ESA modelin mimarisi

Bu çalışmada, ESA'ya daha az ve daha fazla gizli katmanlar ekleyerek sığ ve derin evrişimli sinir ağı modelleri oluşturulmuştur. Evrişimli katmanlar, havuz katmanları ve tam bağlı katmanlar art arda getiririlerek bir ESA modeli kurulmuştur. Bu çalışmada oluşturulan derin ESA modeli, Şekil 4'te görüldüğü gibi dört küme evrişim havuzlama ağ1, bir düzleştirilmiş (flatten) katmanı, üç tam bağlı katman (fully connected layer) ve bir siniflandirıcidan oluşur. Model
39,361,539 parametreye sahiptir ve tam mimari yapısı Şekil 4'te gösterilmiştir.

\subsubsection{AlexNet Model}

Bu çalışmada, Krizhevsky vd. (2012) tarafından geliştirilen evrişimsel sinir ağı olan Alexnet kullanıldı. AlexNet, ESA'ların popüler hale gelmesinde etkili olan bir modeldir. Daha sonra Visual Geometry Group (VGG- Oxford Üniversitesi) tarafindan VGG16 modeli geliştirilmiştir (Toraman \& Bihter, 2020). AlexNet, beş konvolüsyonel (evrişim) katman ve üç tam bağlı katman içerir (Şekil 5). Son tam bağlı katman 1000 sınıfa bağlanır ve ağın geri kalanı bir öznitelik çıkarıcı olarak kabul edilir. AlexNet, çıkış katmanından hemen önce gizli katmanın aktivasyonlarını içeren her görüntü için 4096 boyutlu öznitelik vektörünü sağlar (Abd Almisreb vd., 2018; Özbilgin \& Cengiz, 2020).

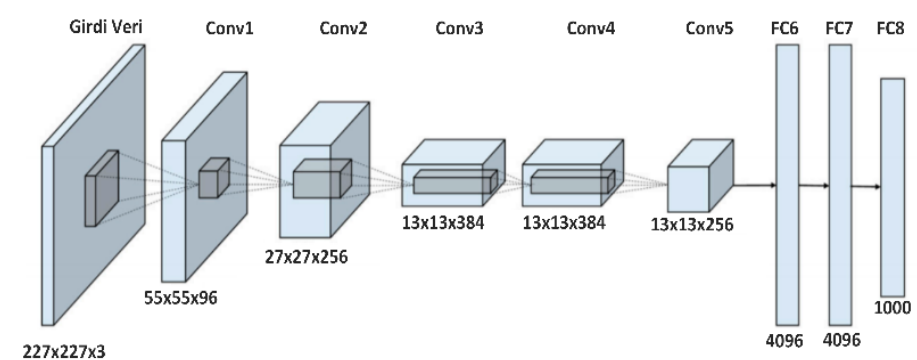

Şekil 5. AlexNet mimarisi (Han vd., 2017)

\subsubsection{VGG16 Modeli}

Simonyan ve Zisserman (2014) tarafindan mevcut ESA'nın derinliği artırılarak VGGNet adında yeni model önerilmiştir. VGG16, 2014 yılında Imagenet yarışmasını kazanmak için kullanılan bir ESA mimarisidir. Ön eğitimsiz bir modeldir. VGG16 orijinal olarak 100000 görüntü içeren ImageNet veri seti kullanılarak eğitilmiştir. $\mathrm{Bu}$ model, bu tarihe kadar önerilen mükemmel görüntü modeli mimarilerinden biri olarak kabul edildi. VGG16, 13 evrişimsel, 5 adet havuzlama ve 3 tam bağlantılı katmandan oluşmaktadır. $\mathrm{Bu}$ model, her bir katmanında evrişim, maksimum havuzlama ve tam bağlı katmanların olduğu 16 gizli katmandan ve $3 \times 3$ 'lük filtrelerden oluşmaktadır. Bu ağ oldukça büyük bir ağdır, ReLU aktivasyon fonksiyonu kullanılmıştır ve yaklaşık 138 milyon parametreye sahiptir.

\subsubsection{VGG19 Modeli}

AlexNet ile karşılaştırıldığında, VGG-19, daha fazla katmana sahip daha derin bir ESA'dır. VGG19, 16 evrişimsel, 5 adet havuzlama ve 3 tam bağlantılı katmandan oluşmaktadır. VGG19'da, VGG16'ya benzer şekilde 5 havuzlama ve son katman olarak SoftMax (sınıflandırıcı)'tan oluşmaktadır. VGG16, 138 milyon parametre içerirken, VGG19 yaklaşık 144 milyon parametre içermektedir (Gopalakrishnan vd., 2017; Toraman \& Bihter, 2020). Bu ESA ağında parametre sayısını azaltmak için, tüm evrişimli katmanlarda 3x3'lük küçük filtreler kullanılmıştır. 2014 yılında Imagenet yarışmasında VGG-19, bir milyondan fazla görüntü üzerinde eğitilmiştir. Sonuç olarak, model geniş bir görüntü yelpazesi için zengin öznitelik temsillerini öğrenmiştir (Zheng vd., 2018).

\subsubsection{ResNet50 Model}

2014 yılında, 14 milyon resmin olduğu (20 binden fazla kategoride olan) ImageNet görüntü veritabanı kullanılarak görüntü tanıma yarışması yapılmıştır (Szegedy vd., 2015). 152 
Resnet50, bu yarışmada veri kümesi üzerinde eğitimi tamamlanmış 50 katmanlı bir ağdır. ResNet iki adet 3x3'lük evirişim katmanı yerine $1 \times 1,3 \times 3$ ve $1 \times 1$ 'lik evrişim katmanları kullanır. ResNet50, 50 katmana sahip kısa bir kalıntı (residual) ağ biçimidir. Resnet50, VGG16 ile karşılaştırıldığında ek bir kimlik (identity mapping) eşleme özelliğine sahiptir. ResNet, bir katmandan diğerine nihai tahmine ulaşmak için gereken deltayı tahmin eder. ResNet50 modeli ESA ağındaki performans düşümü (degradation) problemini çözmeyi amaçlamaktadır. Bozulma problemi, derin ağlar yakınsamaya doğru gittikçe ortaya çıkar. Bu anlamda, doğruluk (accuracy) ağın derinliğine paralel olarak doygunluğa ulaşır ancak daha sonra düşüş eğiliminde hızlanma gözlenir. Dolayısıyla ResNet, katmanlar arası kısa yollar ekleyerek bu problemi çözmeye çalışır. ResNet, gradyanın ilerlemesi için bu alternatif kısa yol yoluna izin vererek kaybolan gradyan problemini azaltır. ResNet'te kullanılan kimlik eşleme, mevcut katman gerekli değilse modelin bir ESA ağırlık katmanını atlamasına izin verir. Bu sayede ağın derinleşmesiyle oluşan bozulmanın önüne geçilmiş olur. $\mathrm{Bu}$, eğitim setine aşırı öğrenme (over-fitting) sorununu önlemeye yardımcı olur (He vd., 2016; Theckedath \& Sedamkar, 2020).

\subsubsection{Inception V3 Model}

Inception V1 (veya GoogLeNet), ILSRVRC 2014'teki yarışmada derin ESA son teknoloji mimarisidir (Rawat \& Wang, 2017). Bu model, ILSVRC 2014 görüntü sinıflandırma yarışmasının galibi olmuştur. ImageNet veri kümesi üzerinde, sınıflandırmada en yüksek başarı ve en düşük hata eldesi kayıtlara geçmiştir. Önceki kazanan AlexNet (ILSVRC 2012 kazanan1) ve ZF-Net (ILSVRC 2013 kazananı) ile karşılaştırıldığında hata oranında önemli bir düşüş sağladı ve VGG'den (2014 ikincisi) önemli ölçüde daha az hata oranı sağladı. Ancak doğruluğu iyileştirmek ve karmaşıklığı azaltmak için modelde iyileştirmeler yapılabilecek bazı noktalar olduğu anlaşılmıştır. Basit Inception (Inception V1)'de ağ ile ilgili en büyük problem görüntü boyutuna göre değişen $5 \times 5$ 'lik evrişimin çok sayıda olması hesaplama açısından maliyeti artmaktadır. Bunun her bir aşamada evrişim katmanının ve havuzlama katmanının çıktısında birleşerek olması çıktı boyutunda büyümeye sebep olur. Bundan dolay1, Inception V2 mimarisinde 5×5'lik evrişim, iki 3×3'lük evrişim ile değiştirilir. $\mathrm{Bu}$ hesaplama süresini azalttığ 1 gibi, dolayısıyla hesaplama hızını da artırır. Çünkü $5 \times 5$ 'lik evrişim, $3 \times 3$ 'lik evrişimden 2.78 kat daha pahalıdır. Dolayısıyla $5 \times 5$ yerine iki $3 \times 3$ katman kullanmak mimarinin performansını artırmaktadır. Inception V3, Inception V1'i temel alır ve doğruluğu daha da artırır. Noktasal evrişim, yığın normalizasyon ve evrişim çarpanlarına ayırma kullanır. VGGNet'e göre daha verimlidir. InceptionV3, 48 katman derinliğindedir ve $1 \times 1,3 \times 3$ ve $5 \times 5$ evrişimli birleştirilmiş katmandan oluşan inception modüllerini kullanır. $5 \times 5$ ve $7 \times 7$ boyutlarında evrişimler yerine iki ya da üç tane $3 \times 3$ boyutlu evrişimler kullanılmaktadır. Bunu yaparak parametre sayısı azalmış ve eğitim hızı artırılmıştır. Inception V3'te amaç, ağın derinlik ve genişliğini eniyileyerek ağdan en yüksek bilgi akışının sağlanması olmuştur. Ağın derinliği arttıkça genişliği de beraberinde artmaktadır (Szegedy vd., 2016).

\subsubsection{Xception Model}

Xception, Google tarafindan Inception'ın extreme sürümü olarak sunulmuştur. Xception, 71 katman derinliğinde evrişimli bir sinir ağıdır. Xception, derinlikte ayrılabilir evrişim ve ResNet'teki gibi evrişim blokları arasındaki kısa yollar şeklinde iki ana noktaya dayanan verimli bir mimaridir. Değiştirilmiş derinlemesine ayrılabilir bir evrişim ile hem ImageNet ILSVRC hem de JFT veri kümeleri için InceptionV3 ile daha iyi performans elde edilmiştir. Xception model; VGGNet, ResNet ve InceptionV3'ten daha iyi performans gösterir. Xception modeli ile derinlemesine ayrılabilir evrişim uygulanmıştır. $\mathrm{Bu}$ önemli ölçüde evrişim işlem maliyetini azaltabilir (Chollet, 2017).

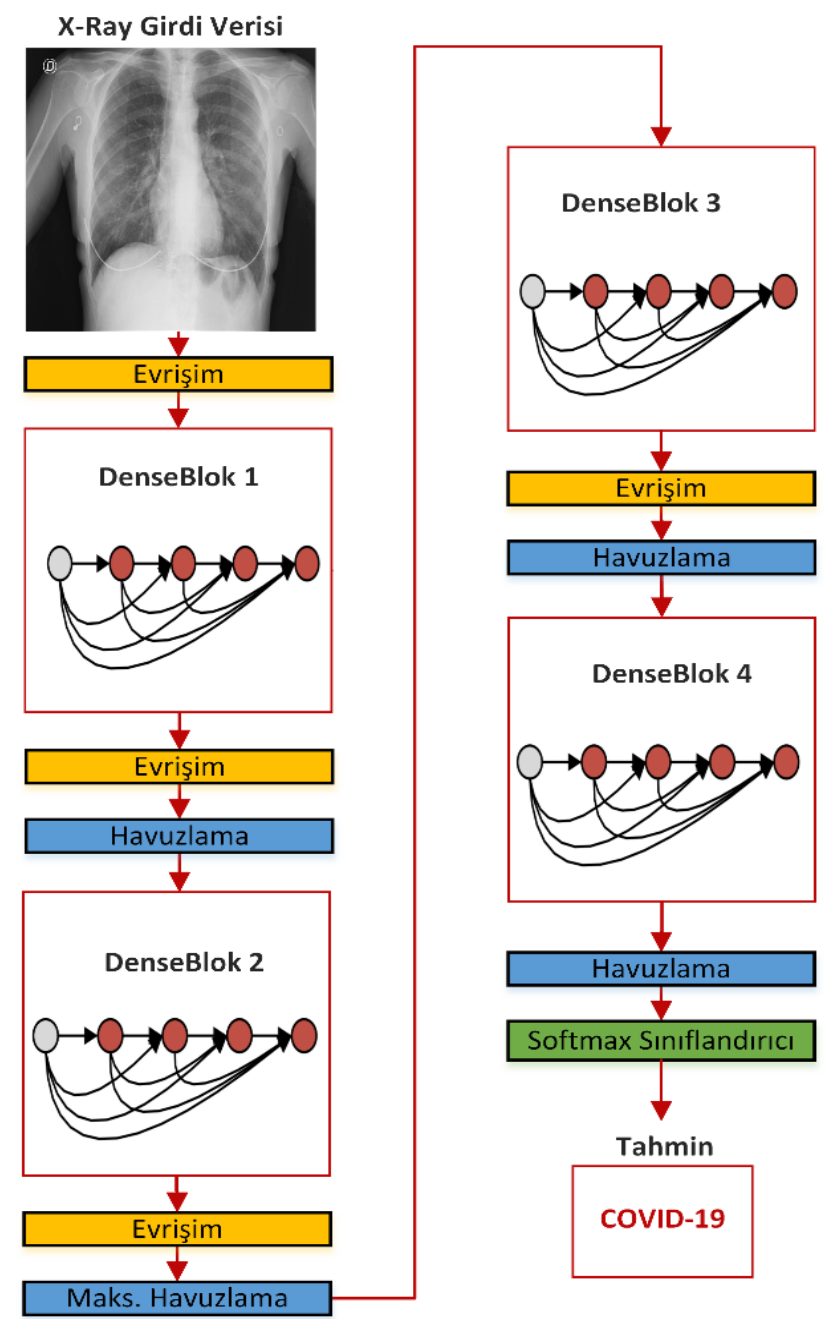

Şekil 6. Bu çalışmada kullanılan DenseNet121 mimarisi

\subsubsection{DenseNet121 Model}

DenseNet (Huang vd., 2017), kaybolan gradyan problemini hafifleterek, özniteliğin yeniden kullanımını artırarak ve parametre kullanımını azaltarak derin öğrenme modellerinin eğitimini yönetilebilir hale getirmiştir. Çeşitli bilgisayarlı görme problemlerinde önemli ölçüde performans vermiştir. DenseNet121'in ana yapı taşı dense bloklarıdır (DenseBlock). $\mathrm{Bu}$ DenseBlock'lar, evrişim katmanlarından oluşur. DenseNet121, nihai çıktı katmanı olarak 1000 birimlik tam bağlı (fully-connected) bir katmana sahip 121 tane bağlanmış evrişimli katmandan oluşur. Genel olarak, ESA mimarileri hiyerarşiktir, bu nedenle $l$-l.katmanın öznitelik haritaları (feature maps) $l$. katmana girdi olarak verilir. Ancak DenseNet'te, önceki tüm katmanların öznitelik haritaları birleştirilir ve herhangi bir belirli katman için girdi olarak kullanılır. Ayrıca, sonraki tüm katmanlar için girdi olarak kendi öznitelik haritaları kullanılır. Dolayısıyla, $l$.katman için, önceki tüm $\mathrm{X}_{0}, \mathrm{X}_{1}, \ldots, \mathrm{X}_{1}-1$ katmanlarının öznitelik haritaları birleştirilir ve girdi olarak kullanılır (Sarker vd., 2021). 
Table 1. Farklı Derin Öğrenme Tekniklerini Performans Değerlendirmesi

\begin{tabular}{|c|c|c|c|c|}
\hline Model & Kesinlik (\%) & Duyarlılık (\%) & F1-Skoru (\%) & Doğruluk (\%) \\
\hline 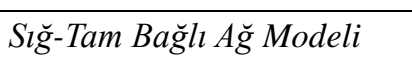 & 90.72 & 90.82 & 90.67 & 90.62 \\
\hline Derin-Tam Bağll Ă̆g Modeli & 92.03 & 92.20 & 92.08 & 92.03 \\
\hline 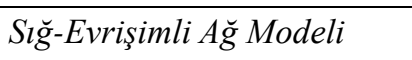 & 94.85 & 94.78 & 94.78 & 94.73 \\
\hline Derin-Evrişimli Ă̆ Modeli & 96.12 & 96.02 & 96.07 & 96.02 \\
\hline AlexNet Model & 95.78 & 95.88 & 95.81 & 95.76 \\
\hline VGG16 Model & 95.90 & 95.90 & 95.84 & 95.76 \\
\hline VGG19 Model & 95.67 & 95.62 & 95.59 & 95.50 \\
\hline ResNet50 Model & 93.50 & 93.50 & 93.41 & 93.32 \\
\hline InceptionV3 Model & 93.70 & 93.88 & 93.75 & 93.70 \\
\hline Xception Model & 95.88 & 95.57 & 95.58 & 95.50 \\
\hline DenseNet121 Model & 97.31 & 97.23 & 97.26 & 97.17 \\
\hline
\end{tabular}

Bu özel model, ağ üzerinden bilgi akışını iyileştirir ve kaybolan gradyan problemini hafifletir. Ayrıca, DenseNet özniteliğin yeniden kullanımını ve parametre verimliliğini geliştirir ve her bir katmana ağın toplu bilgisini sağlar (Kumar vd., 2020). Mimarimiz olarak DenseNet'i seçmemizin en önemli nedeni, yoğun bağlantının düzenlileştirme etkisine sahip olması ve çok büyük olmayan veri üzerinde eğitimde aşırı öğrenmeyi azaltmasıdır. DenseNet121, dört Dense bloğa ve her iki Dense blok arasında bir geçiş katmanına sahiptir (Şekil 6). Her Dense blok birkaç evrişim katmanından oluşur ve her geçiş katmanı bir yığın normalizasyon, bir evrişim ve bir ortalama havuz katmanından oluşur. Doğrusal olmamayı artırmak için DenseNet'te ReLU aktivasyon fonksiyonu kullanılmıştır. Modelimizde, DenseNet121'in son katmanı, giriş görüntüsünden öznitelikleri üreten global bir ortalama havuzlama katmanıdır. $\mathrm{Bu}$ öznitelikler sınıflandırıcı tarafından nihai tahmini yapmak için kullanılır. Sınıflandırıcı için, tam bağlı bir katman ve ardından bir softmax aktivasyon işlevi kullanılmıştır. Üç sınıflı (COVID-19, Viral Pnömonili ve Normal) sınıflandırma için, tam bağlı üç birimlik bir katman kullanılmıştır. Softmax aktivasyonu, tam bağlı katmanın çıktısını normalleştirir ve tahmin edilen çıktı sınıfları üzerinde bir olasılık dağılımı oluşturur.

\section{Deneysel Çalışmalar}

Bu çalışmadaki deneysel çalışmalar, Intel (R) Core (TM) i7 8700U CPU@3.20 GHz işlemcili, 4 GB NVIDIA GeForce GTX 1050 Ti ekran kartlı ve 16GB birincil belleğe sahip masaüstü bilgisayarında gerçekleştirildi. Python 3.7 ve ilgili kütüphaneleri kullanılarak yazılım gerçekleştirildi. Deneysel çalışmada veriler $\% 70$ eğitim, \%10 doğrulama ve \%20 test için ayrılmıştır.

$\mathrm{Bu}$ aşamada farklı derin öğrenme tekniklerinin performansı farklı değerlendirme ölçütleri ile yapıldı. Farklı tekniklerin performans1, kesinlik (precision), duyarlılık (recall), F1-skoru, doğruluk (accuracy) olmak üzere dört performans ölçütü kullanılarak değerlendirildi. Bu değerler, her bir sınıf için hata matrisleri üzerinden hesaplanır (Bozkurt vd., 2020; Erdem \& Bozkurt, 2021; Yağanoğlu \& Irmak, 2021). Tablo 1'de değerlendirme sonuçlarında verildiği gibi, basit yapay sinir ağ1 Sı ̆̆-Tam bağlı ağ model (Bozkurt vd., 2015) ile başlayarak derin ögrenmeye giden süreçte günümüzde popüler olan derin evrişimli sinir ağları kullanıldı. Aynı veri üzerinde farklı sinir e-ISSN: 2148-2683 ağları ve evrişimli sinir ağları tabanlı modelleri koşturularak her birinin performansı kayıt altına alınmıştır. Diğer yöntemlere göre en basit sinir ağı modeli olan Sığ-tam bağlı ağ modelinde dört gizli katman ve her bir katmanda sırasıyla 128,256,128 ve 64 nöron kullanılmıştır. Yapılan deneysel çalışmada, en düşük doğruluk değeri \%90.62 olarak bu modelden elde edilmiştir. Doğruluk performansını daha da iyileştirmek için evrşim sinir ağları kullanarak ağa daha fazla gizli katmanlar ve evrişimli katmanlar eklenmiştir. Örneğin Derin-Evrişimli sinir ağ1 (ESA) modeli, dört küme evrişim havuzlama ağı, bir düzleştirilmiş katmanı, üç tam bağlı katman ve bir sınıflandırıcıdan oluşur. Model 39,361,539 parametreye sahiptir.
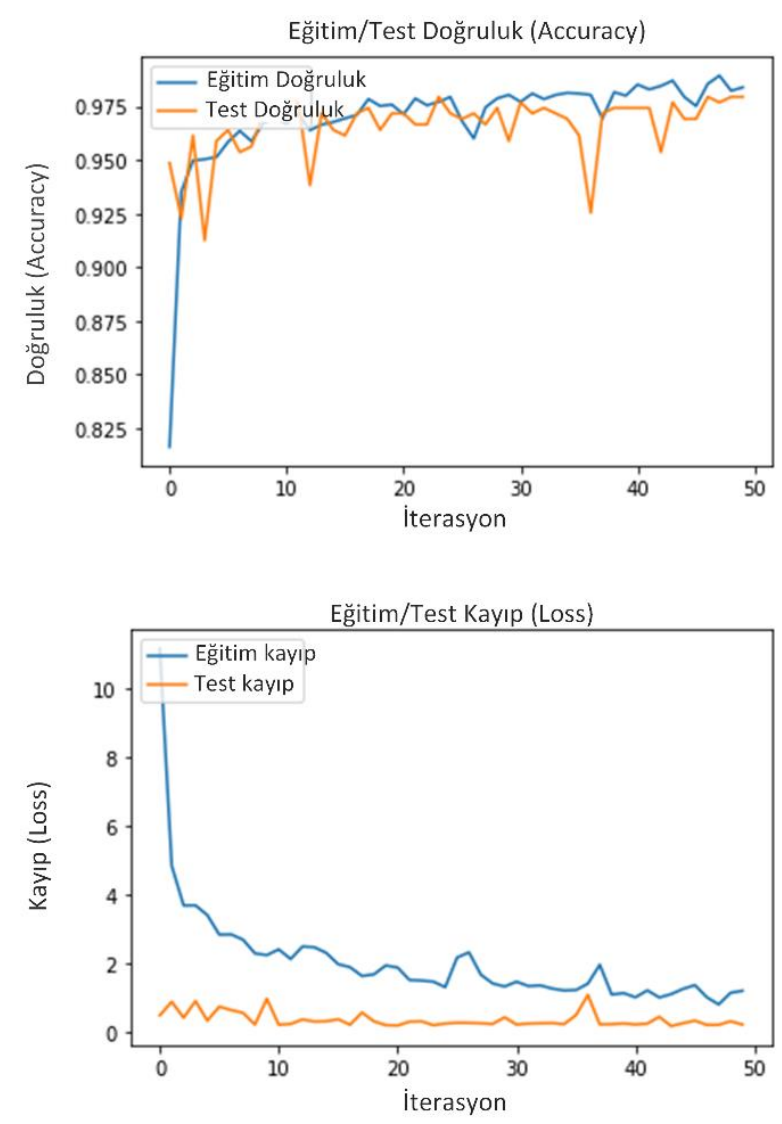

Şekil 7. DenseNet121 modelinin eğitim/test doğruluk ve eğitim/test kayıp grafikleri 


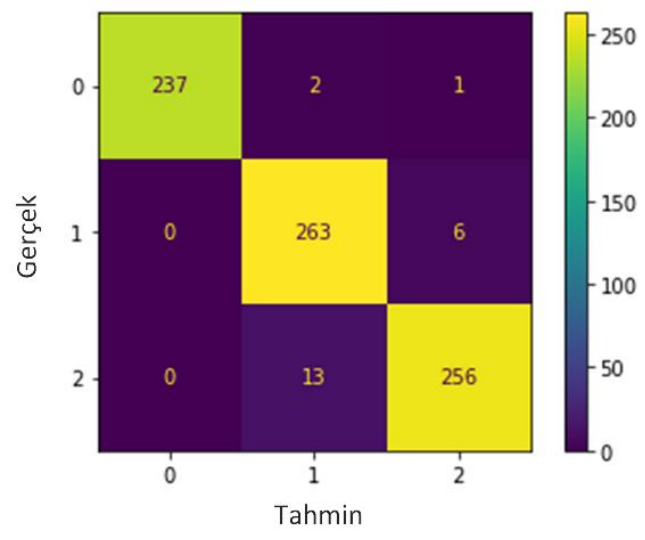

Şekil 8. DenseNet121 modelinden elde edilen hata matrisi

Tablo 1'de görüldüğü gibi, yapılan deneysel çalışmada Derin-Evrişimli ağ modeli ile \%96.02 doğruluk değeri elde edilmiştir. Benzer şekilde ESA'nın gelişmiş sürümlerinden olan ve günümüzde popüler yöntemlerden biri DenseNet121 modeli ile benzer deneysel çalışma yapılmıştır. $\mathrm{Bu}$ model ile bu çalışmada en yüksek doğruluk değeri olan \%97.17'ye ulaşılmıştır. Bu modelin diğer tekniklere göre daha performanslı olduğu gözlemlenmiştir. Şekil 7'da DenseNet121 modelinin 50 iterasyon için eğitim/test doğruluk ve eğitim/test kayıp grafikleri verilmiştir. Hem test hem de eğitim doğruluk eğrileri, iterasyon sayısı arttıkça yükselen bir eğim gösterir. Kayıp eğrisi, Şekil 7'de gösterildiği gibi hata oranındaki düşüşü göstermektedir. Eğitim sürecinin ve ağın öğrenilmesinin iyi bir öğrenme oranında olduğunu göstermektedir. Şekil 7'de görüldüğü gibi her iterasyonda kayıp değeri azalırken verilen eğitim seti ile doğruluk oranı artar ve öğrenme gerçekleşir. Şekil 8'de en yüksek doğruluk değeri elde edilen DenseNet121 modelinin hata (confusion) matrisi verilmiştir. $\mathrm{Bu}$ tabloda 0=COVID-19, $1=$ Viral Pnömoni ve 2=Normal sınıfı temsil etmektedir. Örneğin test verisi için ayrılmış 240 COVID-19 görüntüsünden 237 adet görüntüye ait tahminin doğru yapıldığ şekilde tüm modellerin hata matrisleri çıkarılmış olup bu matrisler üzerinden Tablo 1'deki performans değerleri hesaplanmıştır.

\section{Tartışma ve Sonuç}

Akciğer X-Ray görüntüsü, COVID-19 olmayan pnömonili hastalar için birinci basamak triyaj (hastaların tıbbî olarak sınıflandırılması) işlemi olarak kullanılabilir. Bununla birlikte, COVID-19'un akciğer X-Ray görüntüsü görüntülerinin özellikleri ile diğer enfeksiyonların neden olduğu pnömoni arasındaki benzerlik, radyologların hastalığın tanısını koymada işini zorlaştırmaktadır. Derin öğrenme tabanlı sınıflandırıcıların, COVID-19 hastalarının akciğer X-Ray görüntülerini diğer pnömoni türlerinden güvenilir bir şekilde ayırt edebileceği sonucuna varılmıştır. Bu çalışmada, akciğer X-Ray görüntülerini COVID-19, normal ve viral pnömoni hastalar olarak sınıflandırabilen 11 farklı derin öğrenme tekniğinin aynı veri kümesi üzerinde performans değerlendirmesi ve karşılaştırması yapılmıştır. $\mathrm{Bu}$ çalışmada en basit sinir ağından başlayarak en karmaşı̆̆a doğru sinir ağları ile en iyi tahminleme yöntemi araştırılmıştır. Diğer yöntemlere göre en basit sinir ağı modeli olan Sığ-tam bağlı ağ modeli ile en düşük doğruluk değeri \%90.62 olarak elde edilmiştir. Doğruluk performansını daha da iyileştirmek için evrişim sinir ağları kullanarak ağa daha fazla gizli katmanlar ve evrişimli katmanlar eklenmiştir. Yapılan deneysel çalışmada Derin-Evrişimli sinir ağ modeli ile \%96.02 e-ISSN: 2148-2683 doğruluk değeri elde edilmiştir. Ayrıca ESA'nın gelişmiş sürümlerinden olan ve günümüzde popüler yöntemlerden biri DenseNet121 modeli ile benzer deneysel çalışma yapılmıştır. $\mathrm{Bu}$ model ile bu çalışmada en yüksek doğruluk değeri olan \%97.17'ye ulaşılmıştır. DenseNet121 modelinin diğer tekniklere göre daha performanslı olduğu gözlemlenmiştir. İleri çalışmalarda derin öğrenme tabanlı diğer güncel yaklaşımlar araştırılacak olup, popüler derin öğrenme teknikleri, hibrit yöntemler ve daha fazla veri üzerinde çalışmaların yapılması planlanmaktadir.

\section{Kaynakça}

Abd Almisreb, A., Jamil, N., \& Din, N. M. (2018). Utilizing AlexNet deep transfer learning for ear recognition. In 2018 Fourth International Conference on Information Retrieval and Knowledge Management (CAMP) (pp. 1-5). IEEE.

Asnaoui, K. E., Chawki, Y., \& Idri, A. (2020). Automated methods for detection and classification pneumonia based on $\mathrm{X}$-ray images using deep learning. arXiv preprint arXiv:2003.14363.

Bhandary, A., Prabhu, G. A., Rajinikanth, V., Thanaraj, K. P., Satapathy, S. C., Robbins, D. E., ... \& Raja, N. S. M. (2020). Deep-learning framework to detect lung abnormality-A study with chest X-Ray and lung CT scan images. Pattern Recognition Letters, 129, 271-278.

Bozkurt, F., Altay, Ş. Y., Yaganoğlu, M., (2015). Yapay Sinir Ağları İle Ankara İlinde Hava Kalitesi Sağlı İndeksi Tahmini, 2.Ulusal Yönetim Bilişim Sistemleri Kongresi, Erzurum.

Bozkurt, F., Köse, C., \& Sarı, A. (2020). A texture-based 3D region growing approach for segmentation of ICA through the skull base in CTA. Multimedia Tools and Applications, 79(43), 33253-33278.

Chollet, F. (2017). Xception: Deep learning with depthwise separable convolutions. In Proceedings of the IEEE conference on computer vision and pattern recognition (pp. 1251-1258).

Chouhan, V., Singh, S. K., Khamparia, A., Gupta, D., Tiwari, P., Moreira, C., ... \& De Albuquerque, V. H. C. (2020). A novel transfer learning based approach for pneumonia detection in chest X-ray images. Applied Sciences, 10(2), 559.

Chowdhury, M. E., Rahman, T., Khandakar, A., Mazhar, R., Kadir, M. A., Mahbub, Z. B., ... \& Islam, M. T. (2020). "Can AI help in screening viral and COVID-19 pneumonia?", IEEE Access, 8, 132665-132676.

Dai, W. C., Zhang, H. W., Yu, J., Xu, H. J., Chen, H., Luo, S. P., ... \& Lin, F. (2020). CT imaging and differential diagnosis of COVID-19. Canadian Association of Radiologists Journal, 71(2), 195-200.

Erdem, E., \& Bozkurt, F. (2021). A comparison of various supervised machine learning techniques for prostate cancer prediction. Avrupa Bilim ve Teknoloji Dergisi, (21), 610620.

Gopalakrishnan, K., Khaitan, S.K., Choudhary, A., Agrawal, A. (2017). Deep Convolutional Neural Networks with transfer learning for computer vision-based data-driven pavement distress detection, Constr. Build. Mater. 157, 322-330.

Han, X., Zhong, Y., Cao, L., \& Zhang, L. (2017). Pre-trained alexnet architecture with pyramid pooling and supervision for high spatial resolution remote sensing image scene classification. Remote Sensing, 9(8), 848. 
Hassaballah, M., \& Awad, A. I. (Eds.). (2020). Deep learning in computer vision: principles and applications. CRC Press.

He, K., Zhang, X., Ren, S., \& Sun, J. (2016). Deep residual learning for image recognition. In Proceedings of the IEEE conference on computer vision and pattern recognition,pp. 770-778.

Ho, T. K. K., \& Gwak, J. (2019). Multiple feature integration for classification of thoracic disease in chest radiography. Applied Sciences, 9(19), 4130.

Huang, G., Liu, Z., Van Der Maaten, L., \& Weinberger, K. Q. (2017). Densely connected convolutional networks. In Proceedings of the IEEE conference on computer vision and pattern recognition, pp. 4700-4708.

Ismael, A. M., \& Şengür, A. (2021). Deep learning approaches for COVID-19 detection based on chest X-ray images. Expert Systems with Applications, 164, 114054.

Kesim, E., Dokur, Z., \& Olmez, T. (2019). X-ray chest image classification by a small-sized convolutional neural network. In 2019 scientific meeting on electrical-electronics \& biomedical engineering and computer science (EBBT) (pp. 1-5). IEEE.

Krizhevsky, A., Sutskever, I., \& Hinton, G. E. (2012). Imagenet classification with deep convolutional neural networks. Advances in neural information processing systems, 25, 1097-1105.

Kumar, S., Mishra, S., \& Singh, S. K. (2020). Deep Transfer Learning-based COVID-19 prediction using Chest X-rays. medRxiv.

Li, L., Qin, L., Xu, Z., Yin, Y., Wang, X., Kong, B., ... \& Xia, J. (2020). Artificial intelligence distinguishes COVID-19 from community acquired pneumonia on chest CT. Radiology.

Narin, A., Kaya, C., \& Pamuk, Z. (2020). Automatic detection of coronavirus disease (covid-19) using X-ray images and deep convolutional neural networks. arXiv preprint arXiv:2003.10849.

Oğuz Ç. \& Yağanoğlu, M. (2021). Determination of Covid-19 Possible Cases by Using Deep Learning Techniques, Sakarya Üniversitesi Fen Bilimleri Enstitüsü Dergisi, 25(1), 7-17.

Otter, D. W., Medina, J. R., \& Kalita, J. K. (2020). A survey of the usages of deep learning for natural language processing. IEEE Transactions on Neural Networks and Learning Systems.

Ouchicha, C., Ammor, O., \& Meknassi, M. (2020). CVDNet: A novel deep learning architecture for detection of coronavirus (Covid-19) from chest x-ray images. Chaos, Solitons \& Fractals, 140, 110245.

Özbilgin, F., \& Cengiz, T. E. P. E. (2020). Robotik Uygulamalar İçin Derin Öğrenme Tabanlı Nesne Tespiti ve Sinıflandırması. Karadeniz Fen Bilimleri Dergisi, 10(1), 205-213.

Pathak, Y., Shukla, P. K., Tiwari, A., Stalin, S., \& Singh, S. (2020). Deep transfer learning based classification model for COVID-19 disease. Irbm.

Rawat, W., \& Wang, Z. (2017). Deep convolutional neural networks for image classification: A comprehensive review. Neural computation, 29(9), 2352-2449.

Sarker, L., Islam, M. M., Hannan, T., \& Ahmed, Z. (2021). Covid-densenet: A deep learning architecture to detect covid-19 from chest radiology images.

Simonyan, K., \& Zisserman, A. (2014). Very deep convolutional networks for large-scale image recognition. arXiv preprint arXiv:1409.1556.
Singh, K. K., Siddhartha, M., \& Singh, A. (2020). Diagnosis of Coronavirus Disease (COVID-19) from Chest X-ray images using modified XceptionNet. Romanian Journal of Information Science and Technology, 23(657), 91-115.

Szegedy, C., Liu, W., Jia, Y., Sermanet, P., Reed, S., Anguelov, D., ... \& Rabinovich, A. (2015). Going deeper with convolutions. In Proceedings of the IEEE conference on computer vision and pattern recognition, pp. 1-9.

Szegedy, C., Vanhoucke, V., Ioffe, S., Shlens, J., \& Wojna, Z. (2016). Rethinking the inception architecture for computer vision. In Proceedings of the IEEE conference on computer vision and pattern recognition, pp. 2818-2826.

Theckedath, D., \& Sedamkar, R. R. (2020). Detecting Affect States Using VGG16, ResNet50 and SE-ResNet50 Networks. SN Computer Science, 1(2), 1-7.

Toraman, S., \& Bihter, D. A. Ş. (2020). Evrişimsel sinir ağları kullanılarak normal ve gögüs kanseri hücreleri içeren genomların sinıflandırılması. Dicle Üniversitesi Mühendislik Fakültesi Mühendislik Dergisi, 11(1), 81-90.

Wang, L., Lin, Z. Q., \& Wong, A. (2020). Covid-net: A tailored deep convolutional neural network design for detection of covid-19 cases from chest $\mathrm{x}$-ray images. Scientific Reports, 10(1), 1-12.

WHO. (2020). Coronavirus disease (COVID-19) Pandemic. Erişim: $\quad 15 \quad$ Şubat 2021 https://www.who.int/emergencies/diseases/novelcoronavirus-2019.

Xu, X., Jiang, X., Ma, C., Du, P., Li, X., Lv, S., ... \& Li, L. (2020). A deep learning system to screen novel coronavirus disease 2019 pneumonia. Engineering, 6(10), 1122-1129.

Yağanoğlu, M., \& Irmak, E. (2021). Separation of Incoming EMails Through Artificial Intelligence Techniques. Avrupa Bilim ve Teknoloji Dergisi, (21), 690-696.

Zhao, J., Zhang, Y., He, X., \& Xie, P. (2020). Covid-ct-dataset: a ct scan dataset about covid-19. arXiv preprint arXiv:2003.13865.

Zheng, Y., Yang, C., \& Merkulov, A. (2018). Breast cancer screening using convolutional neural network and follow-up digital mammography. In Computational Imaging III, Vol. 10669, p.1066905, International Society for Optics and Photonics. 